OPEN ACCESS

\title{
Hungarian Adaptation of the Sport Commitment Questionnaire-2 and Test of an Expanded Model with Psychological Variables
}

Authors' contribution:

A) conception and design of the study

B) acquisition of data

C) analysis and interpretation of data

D) manuscript preparation

E) obtaining funding

\author{
Tamás Berki ${ }^{1, \mathrm{~A}-\mathrm{D}}$, Bettina F. Pikó ${ }^{1, \mathrm{~A}, \mathrm{C}, \mathrm{D}}$ and Randy M. Page,
}

${ }^{1}$ University of Szeged, Hungary

${ }^{2}$ Brigham Young University, USA

ABSTRACT

The aims of this study were to adapt the Hungarian version of the Sport Commitment Questionnaire-2 and test an expanded Sport Commitment Model (SCM) with psychological variables.

Participants were 526 adolescent athletes (aged 14-18 years, 52.3\% males). Applied scales were the following: Hungarian version of the Sport Commitment Questionnaire2, Consideration of the Future Consequences Scale and Health Attitudes Scale. Exploratory, confirmatory, and path analysis were used for statistical analysis.

Our result showed adequate construct validity of the Hungarian version of Sport Commitment Questionnaire-2. We found several positive predictors of Enthusiastic Commitment and three positive predictors of Constrained Commitment. We found that Health Attitudes had positive relationship with Constrained Commitment and it was associated with future goals and plans; whereas Enthusiastic Commitment had a positive relationship, and Constrained Commitment had a negative relationship with Future Orientation.

Information about sport commitment provided by Sport Commitment Questionnaire may be useful as a tool to prevent dropout among young athletes.

KEYWORDS

sport commitment, path analysis, future orientation, health attitude, adaptation

\section{Introduction}

Commitment has always received attention as an important element of sport motivation and sport participation. The Sport Commitment Model was introduced to the field of sports psychology in 1993 (Scanlan, Carpenter, Simons, Schmidt, \& Keeler, 1993a) (see figure 1). According to Scanlan's work (1993a), Sport Commitment is defined as "the psychological construct representing the desire and resolve to continue sport participation" (Scanlan et al., 1993a, p. 6). However, researchers have later determined that sport participation did not always stem from desire, but sometimes from duties or obligation as well. Therefore, Constrained Commitment has also been added to the model and defined as "the psychological construct representing 
perceptions of obligation to persist in a sport over time" (Scanlan, Chow, Sousa, Scanlan, \& Knifsend 2016, p. 235).

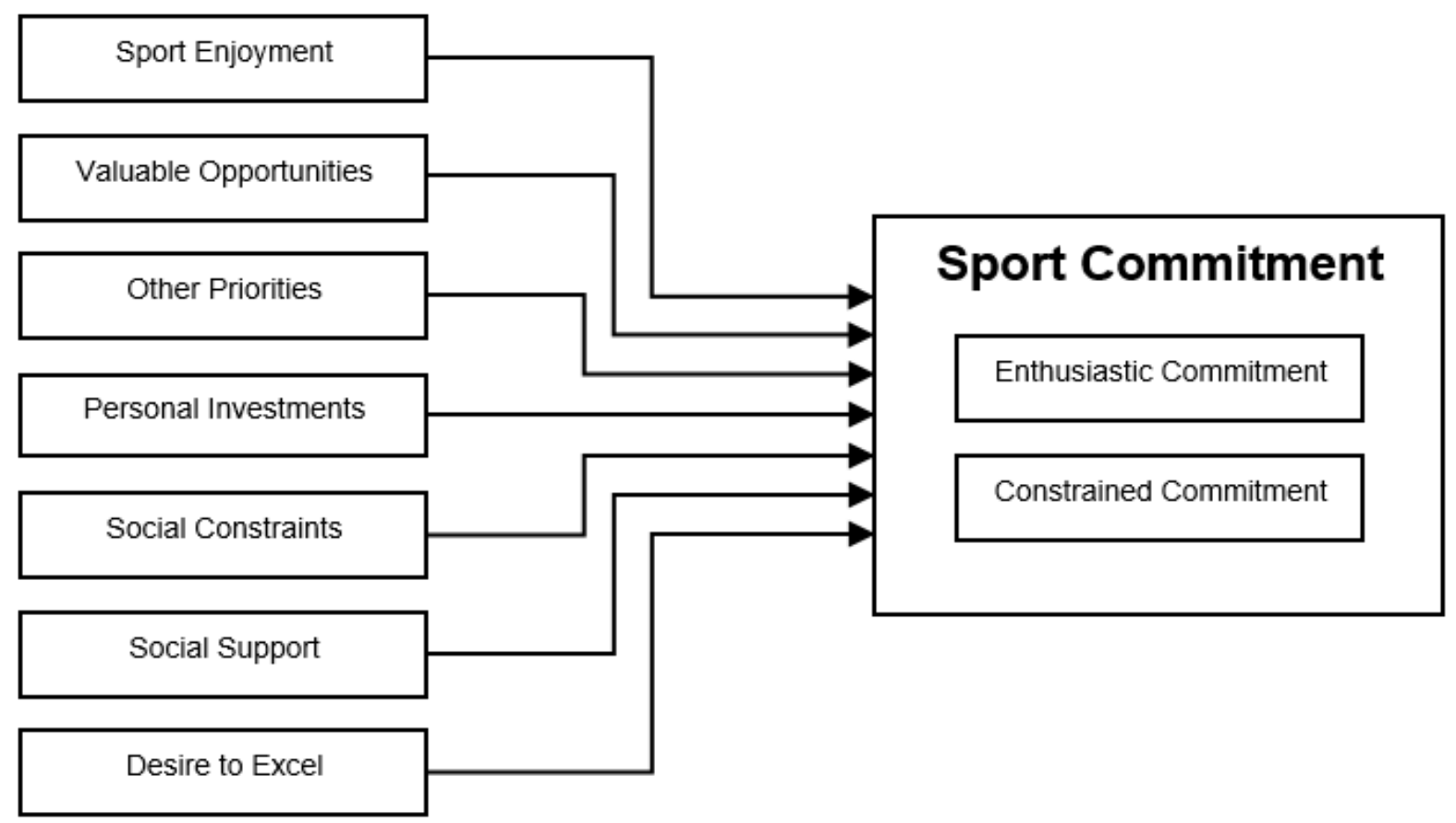

Figure 1. The Sport Commitment Model

Source: Scanlan et al., 2016, p. 234

Determinants of commitment represent seven possible sources of sport commitment. Previous studies showed that Sport Enjoyment and Valuable Opportunities are the most important sources for Enthusiastic Commitment (Carpenter \& Coleman, 1998; Scanlan et al., 2016). Sport Enjoyment was defined as "The positive affective response to a sport experience that reflects generalized feelings of joy" (Scanlan et al., 2016, p. 235), whereas Valuable Opportunities was defined as "Important opportunities that are only present through continued involvement in a sport" (Scanlan et al., 2016, p. 235). Previous studies found that Other Priorities had a negative effect on Enthusiastic Commitment, but positive effect on Constrained Commitment (Wilson et al., 2004, Young $\&$ Medic, 2011). Other Priorities means "alternatives that conflict with continued sport participation" (Scanlan et al., 2016, p. 235). Social Constraints include social expectations that "create perceptions of obligation to remain in a sport" (Scanlan et al., 2016, p. 235). Social Constraints were proposed by Scanlan et al. (1993a) as a positive source of Enthusiastic Commitment, but other researchers found that neither of them had an effect on sport participation (Scanlan et al., 1993b; Sousa, Torregrosa, Vilardich, Villamarín, \& Cruz, 2007) or that they had only weak negative effect (Carpenter, Scanlan, Simons, \& Lobel, 1993; Carpenter \& Scanlan, 1998). There are two approaches to investigating Personal Investment. The first approach is based on the number of personal resources that the athletes put into their sport. The second approach is focused on the notion of loss, by asking athletes to rate how difficult it would be to quit their sport because of the invested personal resources (Scanlan, Russell, Beals, \& Scanlan, 2003; Scanlan, Russell, Scanlan, Klunchoo, \& Chow, 201).

Recently, two sources were added to the model: Social Support and Desire to Excel (Scanlan et al., 2016). Previous studies showed Social Support as having three types (informal, emotional, and instrumental) (Dunkel, Schettel, \& Brooks, 2009). In the original study, Informal and Emotional Social Support were assessed (Scanlan et al., 2016). Social Support was hypothesized as a predictor of Enthusiastic Commitment, but the findings from both quantitative (Carpenter, 1992; Carpenter \& Coleman, 1998, Scanlan et al., 2016) and qualitative (Scanlan, 
Russell, Magyar \& Scanlan, 2009; Scanlan et al., 2013) studies were inconsistent. Qualitative studies also revealed that Desire to Excel was a positive predictor among elite athletes (Scanlan et al., 2009, 2013). These determinants included two subcategories where Mastery Achievement reflected performance for the individual to improve and Social Achievement related to winning and desire to outperform opponents (Scanlan et al., 2013, 2016).

Beyond these possible sources, health attitudes serve an important role in engaging in sports activity (Masten, Dimic, Donko, \& Tusak, 2010; Molanorouzi, Khoo, \& Morris, 2014). Therefore, we expanded the Sport Commitment Model with health attitudes in order to test its role. In addition, previous studies found many positive psychological outcomes to be related to sport participation (e.g., Lee, McInerney, Liem, \& Ortiga, 2010). In view of these benefits, we expanded the Sport Commitment Model to also include future goals in order to emphasize the role of future-orientedness.

Based on the literature pertaining to Sport Commitment and findings from previous studies, this study has two main goals. First, we aimed to adapt the Hungarian version of the Sport Commitment Questionnaire-2. Second, we aimed to test an expanded model of Sport Commitment with the inclusion of scales of future-orientation and health attitudes.

In accordance with the literature (Scanlan et al., 1993b, 2016; Gabriele et al., 2011) we hypothesized that the Hungarian version of the questionnaire contains 12 subscales similar to the original version. Furthermore, we also hypothesized that Sport Enjoyment, Valuable Opportunities, Desire to Excel and Social Support, are positive predictors of the Enthusiastic Commitment. Moreover, we also hypothesized that Other Priorities, Personal Investment and Social Constraints are positive predictors of the Constrained Commitment. We believe that Health attitudes may serve as a new source of Enthusiastic and Constrained type of commitment. Finally, we hypothesized that future-orientedness may have a positive relationship with Enthusiastic Commitment and negative with Constrained Commitment.

\section{Methods}

\section{Participants and procedure}

A total of 526 adolescent athletes (275 males and 251 females) from 38 different sports were involved in this study, ranging from 14 to 18 years of age $(\mathrm{M}=16.5$; $\mathrm{SD}=1.3)$ and they participated in their sports for an average of 8.2 years (S.D. $=3.5)$. Nearly half $(49.2 \%)$ of the participants were representative of individual sports and $50.8 \%$ were representative of team sports. According to training programs, $45.6 \%$ of the athletes spent their time in trainings more than 5 times a week; $26.9 \%$ had trainings 4 or 5 times a week, and 23.2\% had 2-3 trainings weekly. Only $4.2 \%$ reported one training per week. Most engaged in competitive sports: $39.7 \%$ compete at the international level; $34.2 \%$ at the national level; $9.2 \%$ at the municipal or county level; and $16.5 \%$ did not compete at all. More than half of the students (66\%) studied in sport schools and $34 \%$ were in the regular educational system.

After receiving human subjects' approval from the university (IRB), the survey was sent out to twelve different sport schools in Budapest. We chose these sports schools, because they receive support from the Hungarian Olympic Committee and the athletes studying in these schools represent a wide range of sports. At this stage of scale adaptation, it is instrumental to involve athletes from different sporting backgrounds. This provided a large data set which included useful data from athletes with a great variety of sports. Six out of twelve of these schools agreed to participate in this research project, and authorization for participation was given by the school principals. Parents and students were informed about the goals of the study and their consent was obtained. Printed questionnaires were distributed to students and the questionnaires were self-administered, anonymous and voluntary. Personal data, such as names, were not collected from participants. The survey form took approximately 15-20 minutes for students to complete. 


\section{Measures}

Social-Demographic data: The participants provided information on age, gender, educational background, family status, and background of their sport activity.

Sport Commitment Model was measured with the Hungarian version of the Sport Commitment Questionnaire2 (SCQ2-H). Appropriate translation of the original 58-item scale was applied in our study. We followed suggestions of Paic and colleagues (2017) for the adaptation process. First, we translated the questionnaire into Hungarian. This was followed by a small group testing of the suitability of the questionnaire. In the second step of the process, a large data collection was conducted. As a final step of the adaptation, statistical analysis was used to verify the construct validity and the scale reliability. The translation of the scale included several steps (Banville, Desrosiers \& Genet-Volet, 2000). At the first step of this process, it was translated from English to Hungarian, which was followed by back-translation. To improve the content validity, items were translated from English into Hungarian by the researchers under the continuous supervision of highly specialized translators and English teachers. In the next stage, the back-translation was made by an independent expert who was a university English teacher. Finally, these items were compared to ensure that potential participants understood the content of the items. Thus the scale contained 58 items -- similar to the original one -- which could be answered by a five-point Likert-type scale ranging from 1 (Strongly disagree) to 5 (Strongly agree). The Sport Commitment Questionnaire-2 can be divided into 12 different subscales (Scanlan et al., 2016). The Composite Reliability of the original measures varied between .71 and .92, and in our study between .66 and .91.

Future orientation was evaluated with the Consideration of Future Consequences Scale - Short version (CFC; Strathman, Gleicher, Boninger, \& Edwards, 1994). The scale includes six items and contained statements such as "I consider how things might be in the future and try to influence those things with my day to day behavior." The response categories were on a 5-point Likert-type scale, ranging from 1 (extremely uncharacteristic) to 5 (extremely characteristic). The final score varied between 6 and 30 points. The Cronbach alpha value was .50 - similar to a previous study with Hungarian adolescents (Piko, Luszczynska, Gibbons, \& Teközel, 2005).

The Health Attitudes Scale was measured with questions related to appearance, and physical and psychological condition (e.g., "I'm doing sports to lose some weights"; Masten et al., 2010; Molanorouzi et al., 2014). The scale included 8 items and the response categories of the scale were in a 5-point Likert-type scale, ranging from 1 (not agree at all) to 5 (totally agree). The final score varied between 6 and 40 points and the Cronbach alpha value of the scale was .82 with this sample.

\section{Statistical analysis}

Collected data were coded and analyzed using SPSS 22.0 and AMOS 20.0. Following established procedures (Bearden, 2011), data were randomly split into two groups for factorial investigation. A previously established method was used to split our sample (Wong, Mak, \& To, 2015), where 201 participants were involved for the first group and the remaining 325 were involved for the second group. Exploratory factor analysis (EFA) was performed on the first group of the samples to identify factor structures.

Confirmatory factor analysis was performed on the second group of the sample to investigate stability of the construct. The model was assessed by using several fit indexes. These included the Chi square $\left(\chi^{2}\right)$, relative Chi square divided by the degrees of freedom (CMIN/d.f), root mean square error of approximation (RMSEA), a non-normed fit index which also called Tucker-Lewis index (TLI), comparative fit index (CFI), and standardized root mean square residual (SRMR).

Furthermore, path analysis was used to examine the relationship between commitment sources, commitment types, health attitudes, and future-orientation scales (Gerbing \& Hamilton, 1996). 


\section{Results}

\section{Exploratory Factor Analysis}

Exploratory factor analysis (EFA) was used to detect the factor structure of the SCQ2-H. In accordance with suggestions from the literature separate analyses were conducted for subscales representing commitment types and commitment determinants (Gabriele et al., 2011; Scanlan et al., 2016; Wilson et al., 2004).

A series of EFA's using the principal component method with varimax rotation, revealed two types of commitment including 11 items with the minimal loading of .40 (Tabachnick \& Fidel, 2017). The factors accounted for $55.86 \%$ of the variance and the Kaiser-Mayer-Olkin index was .86. The first factor includes six items about willingness to continue sport participation (e.g., "I am determined to keep playing this sport.") which we named Enthusiastic Commitment after the original construct. The factor had an eigenvalue of 4.26 and explained $38.77 \%$ of the variance. The second factor included five items and accounted for $17.08 \%$ of the variance and had an eigenvalue of 1.88. As we expected this factor contained items about obligation to continue sport participation (e.g., "I feel I am forced to keep playing this sport.") which we named the factor as Constrained Commitment.

Subsequently, we analyzed commitment determinants using a series of EFA's principal component method with varimax rotation. The Kaiser-Mayer-Olkin index was .80, which suggested an acceptable fit (Kaiser, 1974). Five items were eliminated for statistical reasons (e.g., low factor loading). One factor with two items was eliminated because it was not relevant to the construct based on theoretical suggestions (Scanlan et al., 2016). The final extraction showed a 10 -factor solution which accounted for $66.1 \%$ of the total variance.

The first factor accounted for $22.40 \%$ of the variance and included five items that we labeled as Sport Enjoyment (eigenvalue: 9.18). It included statements such as "I love to play this sport".

The second factor included five factors and was labeled as Desire to Excel-Mastery (eigenvalue: 3.91). This factor accounted for $9.55 \%$ of the variance and included items about improving sport performance (e.g., "To improve in this sport, I push myself to achieve the goals that I have set").

The next factor assessed statements about investments that can be lost if one stops sport participation. This factor was labeled as Personal Investment-Loss and had four items (e.g., "The time I have spent in this sport makes it difficult to stop playing."). This factor explained $6.17 \%$ of the variance and had an eigenvalue of 2.53 .

The fourth factor accounted for $6.95 \%$ of the variance and included five items (eigenvalue: 2.44 ). It was labeled as Personal Investment-Quantity and contained items such as "I have put a great deal of physical effort into this sport."

Factor 5 was labeled as Desire to Excel-Social (eigenvalue: 1.96; 4.78\% of variance) and included items that reflected outperforming partners or peers (e.g., "In this sport, I strive to be better than my opponents.").

Next was Factor 6 which accounted for 3.55\% of the variance and was labeled as Social Constraints; it included four items (eigenvalue: 1.45). This factor reflected obligation from family or peers (i.e., "People would be disappointed if I didn't keep playing this sport.").

Factor 7 contained four items about other things in life (e.g., " I am being pulled away from this sport by other things in my life."). It was labeled as Other Priorities and accounted for $3.38 \%$ of the variance and had an eigenvalue of 1.39 .

Social Support-Emotional was the next factor and accounted for $3.01 \%$ of the variance (eigenvalue: 1.23 ). It contained questions about support from friends and family and contained three items (e.g., "When I compete in this sport, people who are important to me cheer me on").

Factor 9 was labeled as Valuable Opportunities and accounted for 2.89 of the variance (eigenvalue: 1.18) and included four items about things that only could be experienced through sport participation (e.g., "I would really miss the travel experiences I have if I no longer played this sport."). 
The last factor accounted for $2.76 \%$ of the variance (eigenvalue: 1.13 ) and contained three items about support from coaches and teachers; therefore, it was labeled as Social Support-Informal.

\section{Confirmatory Factor Analysis}

Confirmatory factor analysis (CFA) was used to verify the structural models of commitment. CFA was applied by using data from the second group of the sample $(n=325)$. Similar to the EFA, separate analyses were conducted for subscales representing commitment types and commitment determinants (Gabriele et al., 2011; Scanlan et al., 2016; Wilson et al., 2004).

The first analysis aimed to assess commitment sources and specified a 10-factor model with latent variables. The second analysis assessed the commitment types. These analyses resulted in an acceptable model fit ${ }^{1}$ for the commitment determinants $\left(\mathrm{CMIN} / \mathrm{d} . \mathrm{f} .=1.66 ;\left(\mathrm{X}^{2}(708)=1177.21\right) ; \mathrm{CFI}=.92 ; \mathrm{TLI}=.91 ; \mathrm{RMSEA}=.04 ; \mathrm{SRMR}\right.$ $=.05)$ and perfect model fit for the commitment types $\left(\mathrm{CMIN} / \mathrm{d} . \mathrm{f} .=2.23\left(\mathrm{X}^{2}(41)=91.37\right) \mathrm{CFI}=.96\right.$, TLI $=.95$, RMSEA $=.06$ SRMR $=.07$ ).

Based on the result of the CFA model, several reliability indexes were used for better understanding. Calculated from standardized loading of the items, the AVE (Average Variance Explained) and CR (Composite Reliability) were used to assess the internal reliability for the construct (Fornell \& Larcker, 1981). The Cronbach alpha value was also calculated. According to other researchers (see Fornell \& Larcker, 1981; Hair, Black, Babin, \& Anderson, 2009) the recommended cut off value is .50 for the Ave and .70 for the CR. The CR itself is a good indicator, if AVE is below .50 and CR is above .60 the discriminant validity of the construct is still adequate (Fornell \& Larcker, 1981; Malhotra \& Dash, 2011; Huang, Wang, Wu, \& Wang, 2013). The cut-off value of Cronbach alpha is .70 (Cronbach, 1951). Table 1 shows reliability estimates, including Cronbach alpha values, $\mathrm{CR}, \mathrm{AVE}$ values and inter-correlations of the commitment types and sources. The Cronbach alpha values ranged from .63 to .90 , while the CR values ranged from .69 to .91 . The AVE values ranged from .33 to .61. Some factors did not meet the AVE threshold, but according to the literature (Fornell \& Larcker, 1981; Malhotra \& Dash, 2011), we can accept this value, because of the high CR value. These results suggest that each factor has adequate discriminant validity and measures the intended concept (Hair et al., 2009).

\section{Correlation analysis}

Correlations between the commitment sources and Enthusiastic Commitment were consistent with previous studies (Scanlan et al., 2016). With the exception of Other Priorities and Constrained Commitment, all of the sources of commitment were positively correlated with the Enthusiastic types of commitment. Constrained Commitment was positively related to Social Constraints, Valuable Opportunities, Other Priorities, Desire to Excel-Social, Personal Investment-Loss, Personal Investment-Quantity, and Social Support-Informal, and negatively correlated with Sport Enjoyment, Desire to Excel-Mastery and Social Support-Emotional.

\footnotetext{
${ }^{1}$ Acceptable values: CMIN/d.f $<3.0 ;$ RMSEA $<.08 ;$ TLI $>.90 ;$ CFI $>.90 ;$ IFI $>.90 ;$ SRMR $<.08$
} 
Table 1. Reliabilities and bivariate correlation among factors

\begin{tabular}{|c|c|c|c|c|c|c|c|c|c|c|c|c|c|c|}
\hline & $\alpha$ & CR & AVE & 1 & 2 & 3 & 4 & 5 & 6 & 7 & 8 & 9 & 10 & 11 \\
\hline 1. EC & .90 & .91 & .61 & - & & & & & & & & & & \\
\hline 2. $\mathrm{CC}$ & .63 & .66 & .31 & $-.16^{* *}$ & - & & & & & & & & & \\
\hline 3. SE & .85 & .84 & .52 & $.59^{* * *}$ & $-.34^{* *}$ & - & & & & & & & & \\
\hline 4. $\mathrm{SC}$ & .82 & .81 & .52 & $.39^{* * *}$ & $.32^{* *}$ & $.10^{*}$ & - & & & & & & & \\
\hline 5. OP & .78 & .78 & .47 & $-.23^{* *}$ & $.35^{* *}$ & $-.17^{* * *}$ & .01 & - & & & & & & \\
\hline 6. VO & .75 & .76 & .45 & $.65^{* * *}$ & .07 & $.31^{* *}$ & $.55^{* *}$ & $-.14^{* *}$ & - & & & & & \\
\hline $\begin{array}{l}\text { 7. DE - } \\
\text { Mastery }\end{array}$ & .78 & .82 & .47 & $.72^{* * *}$ & $-.12^{*}$ & $.50^{* *}$ & $.38^{* *}$ & $-.17^{* *}$ & $.58^{* * *}$ & - & & & & \\
\hline $\begin{array}{l}\text { 8. DE - } \\
\text { Social }\end{array}$ & .83 & .78 & .48 & $.54^{* * *}$ & .03 & $.31^{* *}$ & $.44^{* *}$ & $-.12^{*}$ & $.68^{* * *}$ & $.61^{* *}$ & - & & & \\
\hline $\begin{array}{l}\text { 9. PI - } \\
\text { Loss }\end{array}$ & .78 & .79 & .50 & $.40^{* * *}$ & $.32^{* *}$ & .09 & $.51^{* *}$ & .01 & $.44^{* * *}$ & $.39^{* *}$ & $.37^{* * *}$ & - & & \\
\hline $\begin{array}{l}\text { 10. PI - } \\
\text { Quantity }\end{array}$ & .86 & .85 & .53 & $.70^{* * *}$ & .02 & $.34^{* *}$ & $.53^{* *}$ & $-.16^{* *}$ & $.72^{* *}$ & $.67^{* * *}$ & $.68^{* * *}$ & $.48^{* * *}$ & - & \\
\hline $\begin{array}{l}\text { 11. SS - } \\
\text { Emotional }\end{array}$ & .78 & .78 & .55 & $.38^{* * *}$ & -.06 & $.24^{* *}$ & $.40^{* *}$ & $-.17^{* *}$ & $.47^{* * *}$ & $.40^{* *}$ & $.49^{* * *}$ & $.23^{* *}$ & $.47^{* * *}$ & - \\
\hline $\begin{array}{l}\text { 12. SS - } \\
\text { Informal }\end{array}$ & .66 & .79 & .41 & $.33^{* * *}$ & $-.22^{* *}$ & $.11^{*}$ & $.48^{* *}$ & .09 & $.41^{* *}$ & $.25^{* *}$ & $.30^{* * *}$ & $.28^{* * *}$ & $.36^{* *}$ & $.41^{* * *}$ \\
\hline
\end{tabular}

Note. $* \mathrm{p}<.05 * * \mathrm{p}<.01 ; \mathrm{EC}=$ Enthusiastic Commitment; $\mathrm{CC}=$ Constrained Commitment; $\mathrm{SE}=$ Sport Enjoyment; $\mathrm{SC}=$ Social Constraints; OP = Other Priorities; VO = Valuable Opportunities; DE = Desire to Excel; PI = Personal Investment; SS = Social Support; CR = Composite Reliability; AVE = Average Variance Explained.

Source: own study.

\section{Path analysis}

For subsequent analysis, Health Attitudes Scale and Future Orientation Scale were added to the construct in order to appropriately expand this research to other salient features involved in Sport Commitment. Path analysis examined relationships between the commitment sources, health attitudes, future orientation and the two types of commitment (see figure 2). All of the Sport Commitment factors and Health Attitudes were modeled as a predictor of each type of commitment. In turn, each type of commitment was modeled as a predictor of future orientation. Consequently, robust statistics were evaluated to determine the model fit. The indicators for model fit suggest that the resulting model fit the data well ${ }^{2}\left(\mathrm{X}^{2}(23)=.61 .88 ; \mathrm{CMIN} / \mathrm{d} . \mathrm{f} .=2.69 ; \mathrm{CFI}=.98 ; \mathrm{RMSEA}=.06\right.$; SRMR=.03; TLI=.93).

The sources of sport commitment accounted for $72 \%$ of the variance in Enthusiastic Commitment. Results showed that Sport Enjoyment, Valuable Opportunities, Desire to Excel-Mastery, Personal Investment-Quantity were positive predictors for Enthusiastic Commitment. Other Priorities and Social Support-Informal were significant negative correlates of Enthusiastic Commitment.

For Constrained Commitment, commitment sources explained 43\% of the variance. Other Priorities, Personal Investment-Loss, Social Constraints and Social Support-Informal sources were significantly positively related with Constrained Commitment. Sport Enjoyment, Desire to Excel-Mastery, and Social Support-Emotional sources were significantly negatively related.

The expansion of the model showed that Future Orientation had positive relationship with Enthusiastic Commitment, and negative relationship with Constrained Commitment. Health attitudes showed a unique role in this study. Enthusiastic Commitment does not contribute to health attitudes, but health attitudes showed a positive relationship with Constrained Commitment. Therefore, health attitudes might represent a new possible source of Constrained Commitment.

${ }^{2}$ Acceptable values: CMIN/d.f < 3.0; RMSEA < .08; TLI > .90; CFI >.90; IFI >.90; $\mathrm{SRMR}<.08$ 


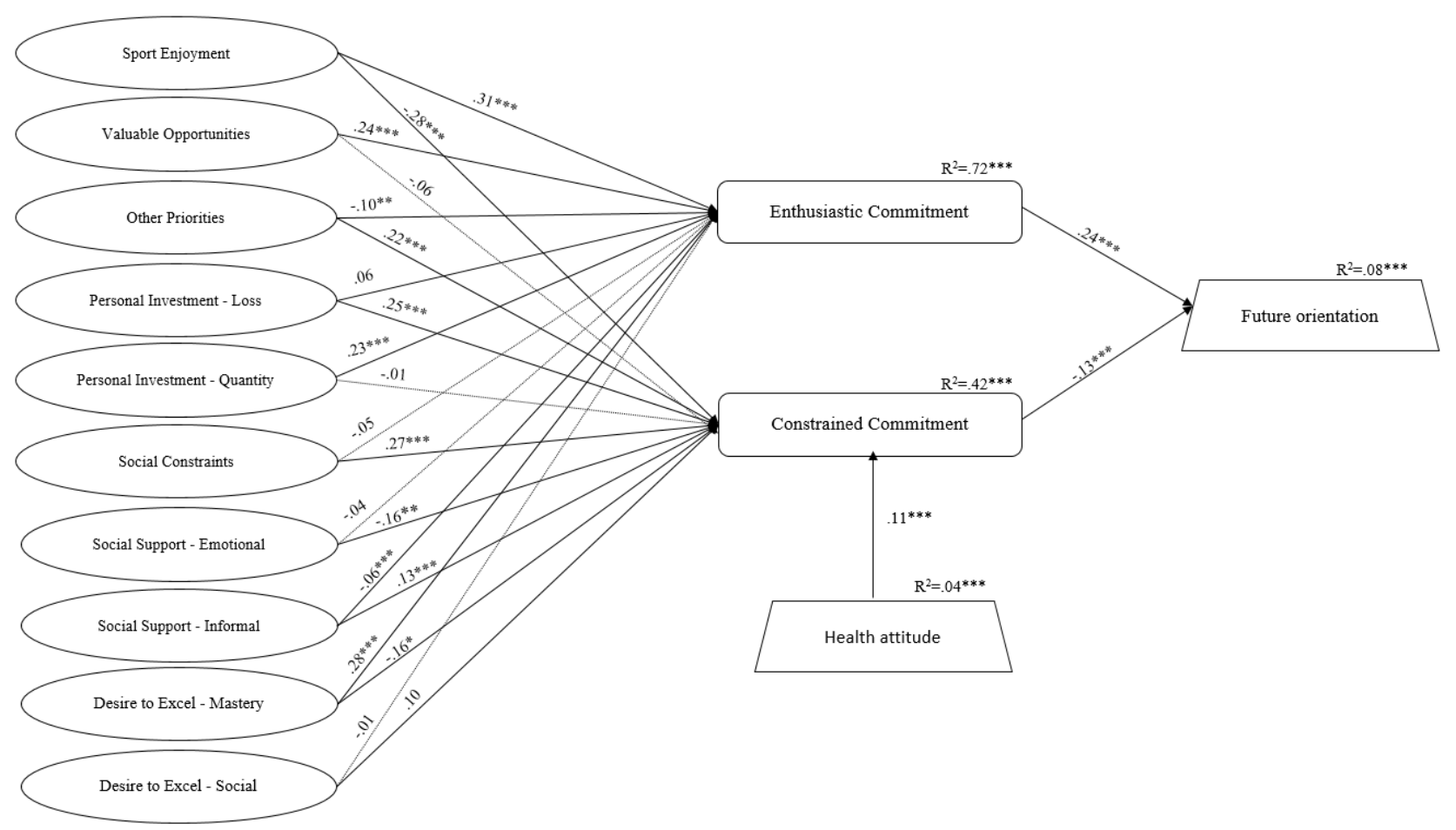

Figure 2. Result of path analysis between types and sources of commitment and psychological variables Source: own study.

\section{Discussion}

Our investigation of the structure of the questionnaire supports our hypothesis that the Hungarian version has the same 12 factor structure as the original version (Scanlan et al., 2016). However, it is important to note that there were differences in items between the original and the Hungarian versions. Only three out of the twelve subscales, including the two types of Commitment and Sport Enjoyment, contained the same items as the original study (Scanlan et al., 2016). The reason why our factors were not entirely identical to the original study might stem from our sample characteristics and cultural differences as suggested in a previous study by Stanley (1996). The original study had a larger sample size of adolescent athletes who competed only in six different sports and this might lower the generalizability of the questionnaire. Unlike Scanlan's (2016) study, our sample included more than thirty different sport types. Further, there are cultural issues which may influence the factor structure such as the management of incongruities of the language of scales (Matsumoto, 2010).

Despite the item differences between the two versions, reliability analysis showed that the scale had adequate internal consistency. Only the Constrained Commitment had reliability issues, but according to other studies, this factor has lower reliability values comparing to other factors (Scanlan et al., 2016; Wilson et al., 2004).

After the scale adaptation, path analysis was used to reveal the relationships between types and sources of commitment. Regarding our hypotheses about Enthusiastic Commitment we found that Sport Enjoyment, Valuable Opportunities, Desire to Excel-Mastery were positive predictors in our model, while Social Support did not strengthen Enthusiastic Commitment. However, Personal Investment-Quantity was found to be a positive source. Sport Enjoyment and Valuable Opportunities were positive predictors of the model. Increased enjoyment of playing appears to result in athletes a feeling that they would miss out of opportunities had they stopped sport participation. These findings are consistent with previous studies (Gabriele et al., 2011; Scanlan et al., 1993b; Scanlan et al., 2016; Sousa et al., 2007). The Desire to Excel-Mastery subcategory represents improving, striving for perfection, and achieving goals (Scanlan et al., 2013). These qualities are essential for a 
competing athlete and can be found in other motivational studies as well (e.g., goal-orientation theory; Lock \& Latham, 1985; Mascret, Elliot, \& Cury, 2015). Desire to Excel appears as an important source of commitment, but only a few studies have explored this in recent years (Scanlan et al., 2013, 2016). These findings are in line with our hypotheses, but the finding about Personal Investment-Quantity was unexpected. The factor showed that athletes who put more energy and resources into sport will likely continue sport participation later into life. While early Commitment studies investigated Personal Investment with the aspect of loss (Scanlan et al, 1993; Carpenter \& Scanlan, 1998), the current study suggests that motivational function of this construct is more complex. Previous studies showed that when athletes rejected the notion of loss this had no effect on their commitment; therefore, researchers added the Personal Investment-Quantity to the model (Scanlan et al, 2003, 2009, 2016).

Other Priorities and Social Support-Informal were found as negative sources of Enthusiastic Commitment. Findings of Other Priorities were consistent with the literature, whereas several studies showed that other aspects of life (i.e., study, family, work, etc.) had negative influence on Enthusiastic Commitment (Gabriele et al., 2011; Scanlan et al., 2016; Sousa et al., 2007). The negative effect of Social Support-Informal was unexpected, but it might be related to advice received from others. These supports may lead to obligatory tendencies in sport participation. Some studies have described the positive role of Social Support similar to our finding, although earlier findings on Social Support show inconsistent findings (Carpenter et al., 1993; Scanlan et al., 1993b, 2016).

Other Priorities, Personal Investment and Social Constraints were positive predictors of the Constrained Commitment as hypothesized, however Social Support-Informal was a positive source.

Four factors (Sport Enjoyment, Desire to Excel-Mastery, Other Priorities, and Social Support-Informal) showed opposite relationship with Constrained Commitment as compared to Enthusiastic Commitment. Sport Enjoyment and Desire to Excel-Mastery were factored together not only with increased Enthusiastic Commitment, but also with decreased level of Constrained Commitment. It appears that high levels of these factors may be essential for Enthusiastic Commitment. Our results for Sport Enjoyment showed consistency with previous research (Scanlan et al., 2016; Weiss \& Weiss, 2003; Wilson et al., 2004), but a previously found negative relationship between Desire to Excel and Constrained Commitment was not confirmed by our study. As detailed earlier in this paper, Other Priorities and Social Support-Informal were associated with decreased Enthusiastic Commitment and Increased Constrained Commitment. In accordance with other research, athletes who had alternatives reported feeling obligated to continue sport participation (Weiss \& Weiss, 2006; Wilson et al., 2004; Young \& Medic, 2011).

We expected that Social Support might be a positive significant predictor of Enthusiastic Commitment. However, we found a positive relationship with Constrained Commitment. Support from peers or coaches may induce obligation, which is represented in Constrained Commitment. Research conducted by Wilson et al. (2004) supports our findings, but other studies have not found this to be the case (Atkins, Johnson, Force, \& Petrie, 2015; Carpenter et al., 1993; Scanlan et al., 2016). These findings likely influenced by cultural features require further research for clarification. Emotional types of Social Support were related to Constrained Commitment as well. This type of support often derives from parents. Several studies revealed that the family has a strong influence on adolescent sport participation (Horn \& Horn, 2012). Yet, on the other hand, this type of influence may entail obligations on youth as Informal type of Social Support. According to early Commitment studies, Personal Investment can be a positive predictor of the Sport Commitment Model (Scanlan et al., 1993a). However, recent studies by Scanlan et al. (2016) suggest that Personal Investment-Loss was a positive predictor of Constrained Commitment. Athletes with high levels of Personal Investment-Loss report feeling that they would not be able to profit from their investments if they were no longer participating in sport.

The role of Health Attitudes has been successfully confirmed in previous motivational studies (Caglar, Canlan, \& Demir, 2009; Molanorozi et al., 2014), but not yet from a commitment perspective. Therefore, we 
hypothesized a relationship of Health Attitudes with both types of commitment. This hypothesis was not confirmed because the Health Attitudes scale was not associated with Enthusiastic Commitment, but had a positive relationship with Constrained Commitment. Thus, our study indicates that striving for healthy lifestyle may co-vary with obligatory participation when it comes to physical activity. Previous studies showed that adolescents tend to participate in physical activity in effort to lose weight, gain muscles, or to be physically fit (Masten et al., 2010), but at the same time place feelings of obligation upon athletes.

Furthermore, we hypothesized that athletes have higher levels of life satisfaction and that they are more oriented toward future goals (e.g., Lee et al., 2010; Lyubomirsky, King, \& Diener, 2005). Our findings provide evidence for this hypothesis. Athletes reporting higher Enthusiastic Commitment also score higher on future-orientation than athletes with higher Constrained Commitment. Thus, in terms of Enthusiastic Commitment, Sport Commitment seems to be a stronger determinant in establishing future goals.

Finally, there are important limitations of our study that need to be discussed. First, we followed the procedure of using randomly split samples (see e.g., Gabriele et al., 2011; Scanlan, et al., 2016; Wilson et al., 2004). Then, we conducted factor analysis with the two separate subsamples. However, our experience in this study suggests that it would be better to collect two independent samples for the EFA and the CFA to justify our result. Second, we found that Enthusiastic Commitment and Social Support-Informal had reliability issues, indicating that future studies will benefit by conducting further analyses of these two constructs. Finally, we investigated the Health Attitudes scale as one factor, but other studies are showing that there may be sub-dimensions of Health Attitudes (e.g., appearance, physical condition) that could receive attention (Molanorozi et al., 2014). Therefore, we suggest that future research includes investigation of these sub-dimensions from a commitment perspective. In addition to addressing these limitations in future research on this topic we also suggest two other directions for advancing the research. First, it seems important to investigate the role of this construct in different types of sports. Second, we advocate that future studies test additional psychological constructs using established psychological scales in order to expand the knowledge base concerning the motivational underpinnings of adolescent athletes.

\section{Conclusion}

Our results support the following major conclusions:

1) Sport Enjoyment, Valuable Opportunities, Desire to Excel, Social Support were positive predictors of Enthusiastic Commitment;

2) However, in contrast, Other Priorities, Personal Investment, Social Constraints were positive predictors of Constrained Commitment;

3) Compared to previous previous research, Health Attitudes appear to be an additional source of Constrained Commitment; although further research is needed to clarify this role;

4) Sport Commitment is also associated with future-orientedness (e.g., Enthusiastic Commitment had a positive relation, Constrained Commitment had a negative relationship with Future Orientation).

In summary, the findings of this study appear to have helpful implications for sport psychologists, coaches, and researchers who are involved in understanding and strengthening the commitment of their clients. Although these findings are not generalizable, our study suggests that the Sport Commitment Questionnaire-2 could be a useful tool for mapping athletes' sources and types of commitments in various athlete populations. This body of research on sport commitment, based on the current research and previous studies appears to be a valuable contribution in better understanding the early stages of intervention to prevent dropout among young athletes. 


\section{REFERENCES}

Atkins, M.R., Johnson, D.M., Force, E.C., \& Petrie, T.A. (2015). Peers, parents, and coaches, oh my! The relation of the motivational climate to boys' intention to continue in sport. Psychology of Sport and Exercise, 16, 170-180.

Banville, D., Desrosiers, P., \& Genet-Volet, Y. (2000). Translating questionnaires and inventories using a cross-cultural translation technique. Journal of Teaching in Physical Education, 19(3), 374-387.

Bearden, W., Netemeyer, R., \& Haws, K. (2011). Handbook of marketing scales: Multi-item measures for marketing and consumer behavior research. Los Angeles: Sage Publications.doi:10.4135/9781412996761

Buckworth, J., Lee, R.E., Regan, G., Schneider, L.K., \& DiClemente, C.C. (2007). Decomposing intrinsic and extrinsic motivation for exercise: Application to stages of motivational readiness. Psychology of Sport and Exercise, 8(4), 441-461.

Caglar, E., Canlan, Y., \& Demir, M. (2009). Recreational exercise motives of adolescents and young adults. Journal of Human Kinetics, 22, 83-89.

Carpenter, P.J. (1992). Staying in sport: Young athletes' motivations for continued involvement. Los Angeles: University of California. Unpublished doctoral dissertation.

Carpenter, P.J., \& Coleman, R. (1998). A longitudinal study of elite youth cricketers' commitment. International Journal of Sport Psychology, 29(3), 195-210.

Carpenter, P.J., \& Scanlan, T.K. (1998). Changes over time in the determinants of sport commitment. Pediatric Exercise Science, 10(4), 356-365. doi:10.1123/pes.10.4.356

Carpenter, P.J., Scanlan, T.K., Simons, J.P., \& Lobel, M. (1993). A test of the sport commitment model using structural equation modeling. Journal of Sport and Exercise Psychology, 15(2), 119-133.

Csikszentmihalyi, M. (1988). The flow experience and its significance for human psychology. Optimal experience, 15-35.

Deci, E.L. \& Ryan, R.M. (1985). Intrinsic motivation and self-determination in human behavior. New York, NY: Plenum Press.

Dunkel Schetter, C., \& Brooks, K. (2009). The nature of SS. In H.T. Reis, \& S. Sprecher (Eds.), Encyclopedia of human relationships (pp. 1565e1570). Thousand Oaks, CA: Sage.

Fornell, C., \& Larcker, D.F. (1981). Evaluating structural equation models with unobservable variables and measurement error. Journal of Marketing Research, 18(1), 39.

Gabriele, J.M., Gill, D.L., \& Adams, C.E. (2011). The roles of want to commitment and have to commitment in explaining physical activity behavior. Journal of Physical Activity and Health, 8(3), 420-428.

Gerbing, D.W., \& Hamilton, J.G. (1996). Viability of exploratory factor analysis as a precursor to confirmatory factor analysis. Structural Equation Modeling, 3, 62-72.

Hair, J.F., Jr., Black, W.C., Babin, B.J., \& Anderson, R.E. (2009). Multivariate data analysis (7th ed.). Upper Saddle River, NJ: Prentice Hall.

Horn, T.S., \& Horn, J.L. (2012). Family influences on children's sport and physical activity participation, behavior, and psychosocial responses. Handbook of Sport Psychology, 685-711.

Ireland, M.J., Clough, B.A., \& Day, J.J. (2017). The cognitive emotion regulation questionnaire: Factorial, convergent, and criterion validity analyses of the full and short versions. Personality and Individual Differences, 110, 90-95.

Kaiser, H.F. (1974). An index of factorial simplicity. Psychometrika, 39(1), 31-36.

Lee, J.Q., McInerney, D.M., Liem, G.A., \& Ortiga, Y.P. (2010). The relationship between future goals and achievement goal orientations: An intrinsic-extrinsic motivation perspective. Contemporary Educational Psychology, 35(4), $264-279$.

Locke, E.A., \& Latham, G.P. (1985). The application of goal setting to sports. Journal of Sport Psychology, 7(3), $205-222$. Lyubomirsky, S., King, L., \& Diener, E. (2005). The benefits of frequent positive affect: Does happiness lead to success? Psychological Bulletin, 131(6), 803-855.

Malhotra, N.K., \& Dash, S. (2011). Marketing research: An applied orientation. London: Pearson Publishing.

Masten, R., Dimec, T., Donko I.A., \& Tusak M. (2010). Motives for sport participation, attitudes to sport and general health status of slovenian armed forces emplyees. Kinesiology, 42(2), 153-163.

Matsumoto, D. (2010). Cross-cultural Research. Handbook of research methods in experimental psychology, $189-208$.

Molanorouzi, K., Khoo, S., \& Morris, T. (2014). Validating the Physical Activity and Leisure Motivation Scale (PALMS). BMC Public Health, 14, 1-15.

Paic, R., Kajos, A., Meszler, B. \& Prisztóka, G. (2017). Validation of the Hungarian Sport Motivation Scale (H SMS). Cognition, Brain, Behavior. An Interdisciplinary Journal, 21(4), 275-291. 
Piko, B.F., Luszczynska, A., Gibbons, F.X., \& Teközel, M. (2005). A culture-based study of personal and social influences of adolescent smoking. European Journal of Public Health, 15(4), 393-398.

Scanlan, T.K., Carpenter, P.J., Simons, J.P., Schmidt, G.W., \& Keeler, B. (1993a). An introduction to the Sport Commitment Model. Journal of Sport and Exercise Psychology, 15(1), 1-15.

Scanlan, T.K., Carpenter, P.J., Simons, J.P., Schmidt, G.W., \& Keeler, B. (1993b). The Sport Commitment Model: Measurement development for the youth-sport domain. Journal of Sport and Exercise Psychology, 15(1), 16-38.

Scanlan, T.K., Chow, G.M., Sousa, C., Scanlan, L.A., \& Knifsend, C.A. (2016). The development of the Sport Commitment Questionnaire-2 (English version). Psychology of Sport and Exercise, 22, 233-246.

Scanlan, T.K., Russell, D.G., Beals, K. P., \& Scanlan, L.A. (2003). Project on Elite Athlete Commitment (PEAK): II. A direct test and expansion of the Sport Commitment Model with elite amateur aportsmen. Journal of Sport and Exercise Psychology, 25(3), 377-401. doi:10.1123/jsep.25.3.377

Scanlan, T.K., Russell, D.G., Magyar, T.M., \& Scanlan, L.A. (2009). Project on Elite Athlete Commitment (PEAK): III. An examination of the external validity across gender, and the expansion and clarification of the Sport Commitment Model. Journal of Sport and Exercise Psychology, 31(6), 685-705.

Scanlan, T.K., Russell, D.G., Scanlan, L.A., Klunchoo, T.J., \& Chow, G.M. (2013). Project on Elite Athlete Commitment (PEAK): IV. Identification of new candidate commitment sources in the Sport Commitment Model. Journal of Sport and Exercise Psychology, 35(5), 525-535. doi:10.1123/jsep.35.5.525

Sousa, C., Torregrosa, M., Vilardich, C., Villamarín, F., \& Cruz, J. (2007). The commitment of young soccer players. Psichothema, 29(2), 256-262.

Standage, M., Gillison, F.B., Ntoumanis, N., \& Treasure, D.C. (2012). Predicting students' physical activity and healthrelated well-being: A prospective cross-domain investigation of motivation across school physical education and exercise settings. Journal of Sport and Exercise Psychology, 34(1), 37-60.

Stanley, L.S. (1996). The development and validation of an instrument to assess attitudes toward cultural diversity and pluralism among preservice physical educators. Educational and Psychological Measurement, 56(5), 891-897.

Strathman, A., Gleicher, F., Boninger, D.S., \& Edwards, C.S. (1994). The consideration of future consequences: Weighing immediate and distant outcomes of behavior. Journal of Personality and Social Psychology, 66(4), 742-752.

Weiss, W.M., \& Weiss, M.R. (2003). Attraction- and entrapment-based commitment among competitive female gymnasts. Journal of Sport and Exercise Psychology, 25(2), 229-247.

Weiss, W.M., \& Weiss, M.R. (2006). A longitudinal analysis of commitment among competitive female gymnasts. Psychology of Sport and Exercise, 7(3), 309-323.

Wilson, P.M., Rodgers, W.M., Carpenter, P.J., Hall, C., Hardy, J., \& Fraser, S.N. (2004). The relationship between commitment and exercise behavior. Psychology of Sport and Exercise, 5(4), 405-421.

Wong, H., Mak, C., \& To, W. (2015). Development of a dental anxiety provoking scale: A pilot study in Hong. Kong. Journal of Dental Sciences, 10(3), pp.240-247.

Young, B.W., \& Medic, N. (2011). Examining social influences on the sport commitment of Masters swimmers. Psychology of Sport and Exercise, 12(2), 168-175.

\section{AUTHOR'S ADDRESS:}

Bettina Piko

University of Szeged

Szentharomsag street 5, 6722 Szeged

Hungary

E-mail: fuzne.piko.bettina@med.u-szeged.hu

Received: 4 June 2018; Accepted: 20 January 2020 